\title{
An Improved Method for Physical Separation of Cerebral Vasculature and Parenchyma Enables Detection of Blood-Brain-Barrier Dysfunction
}

\author{
Frank Matthes ${ }^{1,2,+}+$ D , Hana Matuskova ${ }^{1,2,3,4,+}$, Kajsa Arkelius ${ }^{5}$, Saema Ansar ${ }^{5}$, Iben Lundgaard ${ }^{1,2}$ \\ and Anja Meissner 1,2,4,*(D) \\ 1 Department of Experimental Medical Sciences, Lund University, 22184 Lund, Sweden; \\ frank.matthes@med.lu.se (F.M.); hana.matuskova@dzne.de (H.M.); iben.lundgaard@med.lu.se (I.L.) \\ Wallenberg Centre for Molecular Medicine, Lund University, 22184 Lund, Sweden \\ Department of Neurology, University Hospital Bonn, 53127 Bonn, Germany \\ 4 German Center for Neurodegenerative Diseases, 53127 Bonn, Germany \\ 5 Department of Clinical Sciences, Lund University, 22184 Lund, Sweden; kajsa.arkelius@med.lu.se (K.A.); \\ saema.ansar@med.lu.se (S.A.) \\ * Correspondence: anja.meissner@med.lu.se; Tel.: +46-46-22-20-641 \\ + Equal contribution.
}

check for updates

Citation: Matthes, F.; Matuskova, H.; Arkelius, K.; Ansar, S.; Lundgaard, I.; Meissner, A. An Improved Method for Physical Separation of Cerebral Vasculature and Parenchyma Enables Detection of Blood-Brain-Barrier Dysfunction. NeuroSci 2021, 2, 59-74. https://doi.org/10.3390/neurosci2 010004

Academic Editor:

Xavier Gallart-Palau

Received: 13 November 2020

Accepted: 20 January 2021

Published: 1 February 2021

Publisher's Note: MDPI stays neutral with regard to jurisdictional claims in published maps and institutional affiliations.

Copyright: (c) 2021 by the authors. Licensee MDPI, Basel, Switzerland. This article is an open access article distributed under the terms and conditions of the Creative Commons Attribution (CC BY) license (https:/ / creativecommons.org/licenses/by/ $4.0 /)$.

\begin{abstract}
The neurovascular niche is crucial for constant blood supply and blood-brain barrier (BBB) function and is altered in a number of different neurological conditions, making this an intensely active field of research. Brain vasculature is unique for its tight association of endothelial cells with astrocytic endfeet processes. Separation of the vascular compartment by centrifugation-based methods confirmed enrichment of astrocytic endfeet processes, making it possible to study the entire vascular niche with such methods. Several centrifugation-based separation protocols are found in the literature; however, with some constraints which limit their applicability and the scope of the studies. Here, we describe and validate a protocol for physically separating the neurovascular niche from the parenchyma, which is optimized for smaller tissue quantities. Using endothelial, neuronal, and astrocyte markers, we show that quantitative Western blot-based target detection can be performed of both the vessel-enriched and parenchymal fractions using as little as a single mouse brain hemisphere. Validation of our protocol in rodent stroke models by detecting changes in tight junction protein expression, serum albumin signals and astrocyte activation, i.e., increased glial fibrillary acidic protein expression, between the ipsilateral and the lesion-free contralateral hemisphere demonstrates this protocol as a new way of detecting BBB breakdown and astrogliosis, respectively.
\end{abstract}

Keywords: cerebral vasculature; vascular fractionation protocol; neurovascular niche; blood-brain barrier; stroke

\section{Introduction}

The cerebral vasculature has unique properties since the transfer of molecules to the brain parenchyma is tightly regulated by the blood-brain barrier (BBB) [1,2]. Vascular functions can be impaired in diverse neuropathological conditions [3] thus, not only disturbing proper distribution of metabolites within the brain but also limiting its capability to protect neurotoxic substances from entering the brain $[4,5]$. Studies have shown involvement of BBB dysfunctions and cerebral blood flow deficits in the pathogenesis of neurodegenerative diseases such as Alzheimer's disease, Parkinson's disease, and amyotrophic lateral sclerosis [3,6,7]. During stroke, disruption of the BBB can lead to secondary damage such as brain edema or hemorrhagic transformation, and to the infiltration of immune cells [8]. Investigations of brain vasculature in such disease conditions require in vivo studies because of the complexity of disease pathologies and the variety of cell types involved. Therefore, research relies in part on animal models, and quantitative methods are needed in order to 
elaborate on the precise mechanisms behind pathology, which in turn eventually leads to the development of new therapeutic strategies.

To study cerebral vasculature, several protocols for purifying mouse brain vessels or generating brain vessel-enriched fractions have been published [9-11]. Purified vessels have been investigated using immunofluorescence stainings and Western blotting, but studies usually focus on the purified vessels alone, without comparison to the remaining brain parenchyma. In a recent study, we used a protocol that was slightly modified from a previously published protocol [9] to study vascular polarization of astrocyte endfeet in platelet-derived growth factor B retention-motif knockout (PDGF-B ${ }^{\text {ret }} / \mathrm{ret}$ ) mice during development [12]. Several limitations, including the presence of high concentrations of bovine serum albumin and high tissue quantity requirements that necessitated pooling of several mouse brains for Western blot-based quantification led us to further modify the previously published mouse brain vessel isolation method. Our modified method permits Western blot analyses of brain vessel-enriched and brain parenchyma fractions from the same tissue sample utilizing only one mouse brain hemisphere, thus enabling investigations requiring the direct comparison of the two brain hemispheres from the same animal, such as in stroke research. Here, we validate the applicability of a modified brain vessel - parenchyma fractionation method in a murine and rat stroke model. As our modified method yields intact microvessel fractions with discrete BBB components (endothelial cells, pericytes and astrocyte endfeet), we further demonstrate its suitability for analysis of BBB integrity.

\section{Materials and Methods}

\subsection{Chemicals and Reagents}

All chemical reagents and solutions were purchased from Fisher Scientific (Göteborg, Sweden), Saveen and Werner (Limhamn, Sweden) or Sigma-Aldrich (Stockholm, Sweden) unless otherwise stated. Commercially available primary antibodies against VE-Cadherin, eNOS and SNAP-25 (Abcam, Cambridge, UK), GFAP (Dako Agilent, Kista, Sweden), aquaporin-4 (EMD Millipore, Darmstadt, Germany), beta-tubulin, beta-actin and alphaSMA (Sigma-Aldrich, Stockholm, Sweden), and human/mouse serum-albumin (Biotechne, Abingdon, UK) were used for immunodetection. Donkey anti-mouse and donkey antirabbit HRP-coupled secondary antibodies or Alexa Fluor 680 donkey anti-goat (Nordic Biosite, Täby, Sweden) secondary antibodies were used for visualization.

\subsection{Animals}

This investigation conforms to the Guide for Care and Use of Laboratory Animals published by the European Union (Directive 2010/63/EU) and with the ARRIVE guidelines. All animal care and experimental protocols were approved by the institutional animal ethics committee at Lund University (Dnr.: 5.8.18-12657/2017 and 5.8.18-10593/2020) and LANUV NRW (81-02.04.2019.A214/01) and were conducted in accordance with European animal protection laws. Wild type C57Bl/6N were obtained from Taconic (Ejby, Denmark) and housed in a conventional animal facility under standard conditions with a 12:12 $\mathrm{h}$ light-dark cycle and access to food (standard rodent diet) and water ad libitum. Mice were housed in groups of four to five in conventional transparent polycarbonate cages. Rats were housed in groups of two in conventional transparent polycarbonate cages.

\subsection{Permanent Middle Cerebral Artery Occlusion (MCAo) in Mice}

Three-months old male mice were anesthetized with isofluorane (IsoFlo ${ }^{\circledR}$ vet $100 \%$; Abbott, Sweden, $2 \%$ at $1.5 \mathrm{~L} / \mathrm{min}$ in room air) using a vaporizer (Tec-3, Cyprane Ltd., Keighley, UK). During the procedure, the body temperature was maintained at $36.5 \pm 0.5^{\circ} \mathrm{C}$. Between the orbit and the external auditory meatus $1 \mathrm{~cm}$ skin incision was made and the temporal muscle was separated from the skull by electrocoagulation forceps (ICC50, Erbe, Germany). The MCA bifurcation was identified, and a 1-2 $\mathrm{mm}$ hole was drilled above it in the rostral part of the temporal area. The proximal part of the MCA was occluded 
by short electrocoagulation followed by transection of the vessel to ensure the permanent occlusion. The temporal muscle was placed to its original position and the wound was sutured. Following surgery, animals received intraperitoneal injections of Buprenorphine $(0.1 \mathrm{mg} / \mathrm{kg})$ for pain relief and subcutaneous injection of saline to prevent dehydration.

\subsection{Thromboembolic Stroke in Rats}

Thromboembolic stroke was induced by local injection of $\alpha$-thrombin directly into the lumen of the right middle cerebral artery (MCA) in male Wistar rats (299-385 g; Janvier, France) as recently described [13]. Rats were anesthetized using 3\% isoflurane and maintained with $1.5-2 \%$ isoflurane in $\mathrm{N}_{2} \mathrm{O}: \mathrm{O}_{2}$ (70:30). An electric temperature probe was inserted into the rectum of the rat to record the temperature, and found it to be maintained at $37^{\circ} \mathrm{C}$. The rat was placed in a stereotactic device, and the temporal muscle was retracted. A craniectomy was performed, the dura was excised, and the MCA was exposed. The laser Doppler flow probe (AD Instruments, Oxford, UK) was placed over the MCA territory for monitoring the CBF during the duration of the surgery. A micropipette filled with 12 UI human $\alpha$-thrombin (4 UI/ $\mu \mathrm{L}$, Nordic Diagnostica AB, Kungsbacka, Sweden) was introduced into the lumen of the MCA bifurcation and injected carefully to induce the formation of a clot in situ. The pipette was removed $20 \mathrm{~min}$ after the injection at which time the clot had stabilized. To minimize suffering, the rats received Marcaine $(1.25 \mathrm{mg} / \mathrm{kg}$, AstraZeneca) at the site of incisions as analgesics and eye gel (Viscotears) to prevent the cornea from drying out during surgical procedure. A subcutaneous injection of $10 \mathrm{~mL}$ of isotonic saline for rehydration was given at the end of the surgery.

\subsection{Brain Vessel-Parenchyma Fractionation}

Brain vessels were separated from parenchyma by a procedure modified from Boulay et al. [9]. The original protocol was scaled down for use with one mouse brain hemisphere [or one rat brain hemisphere]. Animals were transcardially perfused with PBS and brains were collected on ice. All buffers were precooled on ice. One brain hemisphere was minced to small pieces with a scalpel in $1 \mathrm{~mL}$ B1 (HBSS with $10 \mathrm{mM}$ HEPES) [rat: $3 \mathrm{~mL}$ ]. The sample was homogenized using a long $21 \mathrm{G}$ cannula $(0.8 \mathrm{~mm} \times 120 \mathrm{~mm})$ mounted on a $2 \mathrm{~mL}$ syringe [rat: $5 \mathrm{~mL}$ syringe] by aspirating and pushing out 20 times. The homogenate was transferred to a $2 \mathrm{~mL}$ tube [rat: $15 \mathrm{~mL}$ tube] and centrifuged in a fixed-angle rotor at $2000 \times g$ and $4{ }^{\circ} \mathrm{C}$ for $10 \mathrm{~min}$. The supernatant, representing the parenchyma fraction, was taken off and mixed with an equal volume of $2 x$ RIPA buffer including protease and phosphatase inhibitor cocktails before freezing on dry ice and storing at $-80{ }^{\circ} \mathrm{C}$. The pellet containing the vessels was resuspended in $2 \mathrm{~mL}$ B2 (B1 with $18 \%(w / v)$ dextran, $\mathrm{M}_{\mathrm{r}} \approx 70,000$ ) [rat: $6 \mathrm{~mL}$ ] by vigorous shaking, and centrifuged at $4400 \times g$ and $4{ }^{\circ} \mathrm{C}$ for $15 \mathrm{~min}$. The supernatant including the myelin layer was carefully removed and the pellet was resuspended in $1 \mathrm{~mL}$ B3 (B1 with 1\% ( $w / v)$ BSA). Brain vessels were collected on a $20 \mu \mathrm{m}$ mini cell strainer (pluriSelect, Leipzig, Germany) by centrifugation at $200 \times g$ for $1 \mathrm{~min}$ in a swinging bucket rotor. Vessels were washed twice by resuspending in $1 \mathrm{~mL}$ B3 on the strainer and subsequent centrifugation. The purified vessels were taken up in $1 \mathrm{~mL}$ B3 by rinsing the strainer, transferred to a $1.5 \mathrm{~mL}$ tube, and sedimented at $2000 \times g$ and $4{ }^{\circ} \mathrm{C}$ for $5 \mathrm{~min}$. To remove BSA the supernatant was discarded and the pellet was carefully resuspended in $1 \mathrm{~mL} \mathrm{B1}$, followed by centrifugation at $2000 \times \mathrm{g}$ and $4{ }^{\circ} \mathrm{C}$ for $5 \mathrm{~min}$. The supernatant was removed completely, and the vessels were frozen on dry ice and stored at $-80^{\circ} \mathrm{C}$.

\subsection{Western Blotting}

To extract proteins purified vessels were thawed by mixing with $100 \mu \mathrm{L}$ RIPA buffer containing $10 \mathrm{mM}$ Tris ( $\mathrm{pH} 8.0), 1 \mathrm{mM}$ EDTA, $1 \%$ Triton X-100, $0.1 \%$ sodium deoxycholate, $0.1 \%$ SDS, $140 \mathrm{mM} \mathrm{NaCl}$ and protease and phosphatase inhibitor cocktails (Merck, Darmstadt, Germany), and homogenized in a glass micro homogenizer (Radnoti, Dublin, Ireland) with at least 20 strokes. Parenchyma samples, which had been frozen after mixing with $2 \times$ 
RIPA buffer, were thawed on ice. Vessel and parenchyma samples were mixed vigorously, incubated on ice for $30 \mathrm{~min}$, mixed vigorously again, and insoluble material was removed by centrifugation at $20,000 \times g$ and $4{ }^{\circ} \mathrm{C}$ for $10 \mathrm{~min}$. Protein concentration was determined by Pierce BCA protein assay (Fisher Scientific, Sweden). Western blotting was carried out according to standard protocols. Briefly, samples were mixed with $4 \mathrm{x}$ sample buffer (0.2 M Tris pH 6.8, 8\% SDS, 40\% (v/v) glycerol, 20\% (v/v) $\beta$-mercaptoethanol, $0.02 \%(w / v)$ bromophenol blue) and heated for $10 \mathrm{~min}$ at $95{ }^{\circ} \mathrm{C}$. Proteins were separated on $10 \%$ or $12 \%$ SDS-PAGE mini gels and transferred onto PVDF membranes (Biorad, Sweden). Membranes were blocked for $30 \mathrm{~min}$ in $1 \%$ bovine serum albumin (in phosphate-buffered saline containing 1\% Tween-20 (PBST); $137 \mathrm{mM} \mathrm{NaCl}, 2.7 \mathrm{mM} \mathrm{KCl}, 10 \mathrm{mM} \mathrm{Na}_{2} \mathrm{HPO}_{4}, 1.8 \mathrm{mM}$ $\mathrm{KH}_{2} \mathrm{PO}_{4} ; \mathrm{pH}$ 7.4) and sequentially incubated with the primary and secondary antibodies. An antibody-specific dilution for the primary antibodies and 1:10,000 for the HRP-labeled secondary antibody were utilized. All antibodies were diluted in $1 \%$ bovine serum albumin or 5\% milk in PBST. A standard chemiluminescence procedure (ECL Plus) was used to visualize protein binding. The developed membranes were evaluated densitometrically using Image Lab 6.0.1 (Biorad, Solna, Sweden).

\subsection{Vessel Fraction Histology}

Subsequent to brain vessel-parenchyma fractionation, the vessel-enriched fraction was subjected to histological assessment. The vessel fraction was washed with PBS (137 mM $\mathrm{NaCl}, 2.7 \mathrm{mM} \mathrm{KCl}, 10 \mathrm{mM} \mathrm{Na} \mathrm{HPO}_{4}, 1.8 \mathrm{mM} \mathrm{KH}_{2} \mathrm{PO}_{4} ; \mathrm{pH} 7.4$ ) and either plated on microscope slides for immediate phase-contrast visualization or further processed for immunofluorescence staining. Vessel fractions for immunofluorescent assessment of cerebrovascular marker expression were processed in $0.5 \mathrm{~mL}$ plastic reaction tubes. Vessels were fixed using $4 \%$ paraformaldehyde for $30 \mathrm{~min}$ followed by three washes with PBS and $15 \mathrm{~min}$ permeabilization using hybridization buffer (ROCHE, Germany) prior to an overnight incubation with antibody cocktails containing $\alpha$-SM-actin (1:500) and Aqp4 (1:250) or eNOS $(1: 250)$ and GFAP $(1: 250)$ at $4{ }^{\circ} \mathrm{C}$. Following three washes with PBS, vessel fractions were incubated in antibody cocktails containing AlexaFluor-488 goat anti-mouse and AlexaFluor-594 goat anti-rabbit secondary antibodies (1:1000) for $2 \mathrm{~h}$ at room temperature. Vessels were washed with PBS and mounted on glass slides (Superfrost; VWR, Stockholm, Sweden) for embedding with DAPI-containing mounting media (FluoroMount G; Thermo Fisher, Göteborg, Sweden). Phase-contrast and immunofluorescence visualization was performed using an Olympus BX60 with DP72 camera and CellSens1.5 software.

\subsection{Statistics}

All data are expressed as mean \pm SEM, where $n$ is the number of animals. For comparison of two groups, a two-tailed unpaired $t$-test was utilized. Differences were considered significant at error probabilities of $p \leq 0.05$.

\section{Results}

3.1. Separation of Brain Vessel-Enriched and Vessel-Depleted Parenchyma Fractions from Single Mouse Brain Hemispheres

Previously published mouse brain vessels purification protocols have been used for subsequent immunofluorescence stainings and Western blotting, however, these studies usually focused on the purified vessels alone, without comparison to the remaining brain parenchyma, or using total brain homogenate for comparison. Our goal was to investigate how a modified mouse brain vessel isolation method could permit Western blot analyses of brain vessel-enriched fraction and brain parenchyma fraction from the same tissue sample. Another objective was to reduce the amount of tissue needed enough to enable investigations that require direct comparison of the two brain hemispheres from the same mouse, e.g., in stroke research.

First, we modified a previously published procedure [9] and successfully reduced tissue requirements to one mouse brain hemisphere. Specifically, volumes of liquids and 
centrifugation devices were scaled down, tissue was homogenized using a cannula and a small syringe instead of a dounce homogenizer, and the vessel- and myelin-depleted parenchyma fraction was collected (Figure 1; experimental details in Method section). At the end of the procedure, 20-80 $\mu \mathrm{g}$ of total protein could be extracted from purified vessels of one mouse brain hemisphere, which was sufficient for several Western blot experiments.

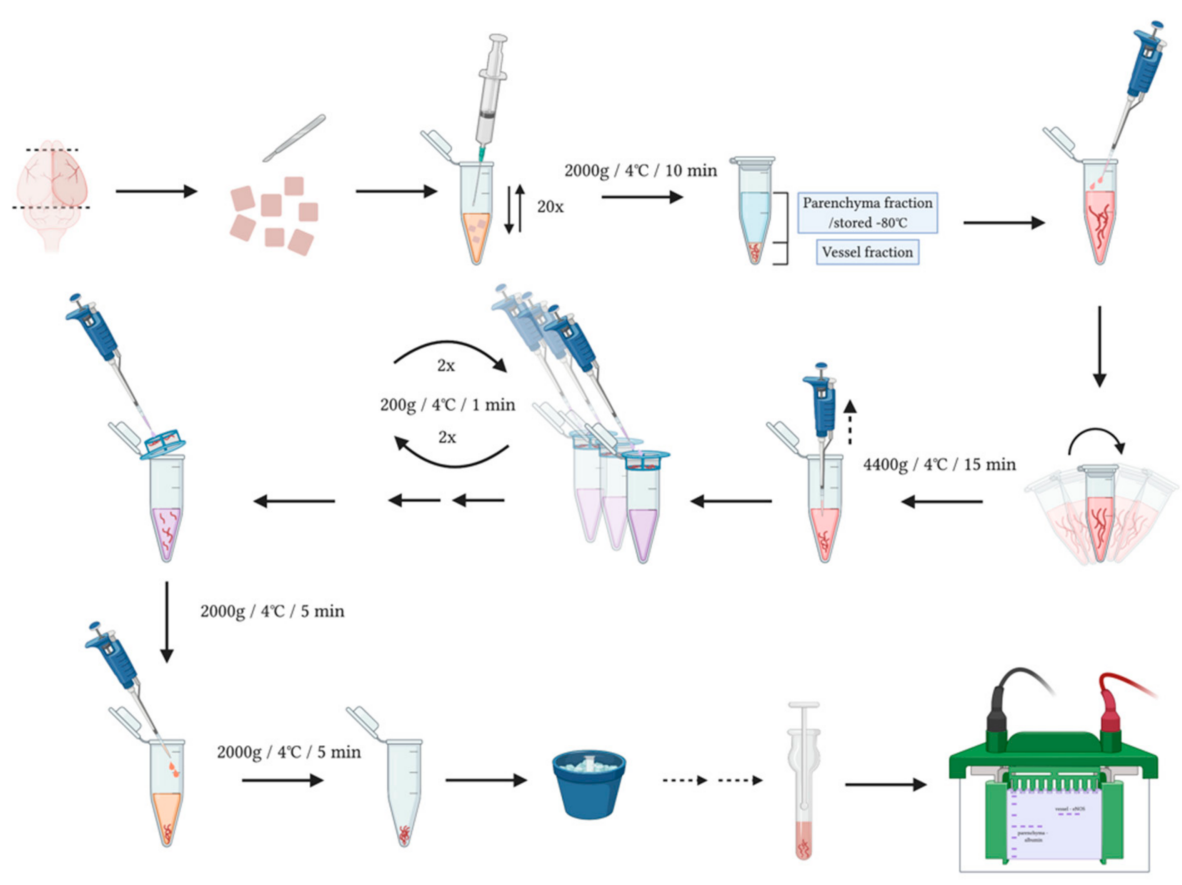

Figure 1. Separation of the vessel and parenchyma fraction from mouse brain hemispheres. Mouse brain was split sagitally by the interhemispheric fissure into two hemispheres. Each hemisphere was minced to small pieces with a scalpel and subjected to homogenization using a long $21 \mathrm{G}$ cannula. The homogenate was centrifuged and the supernatant, representing the parenchyma fraction, processed for protein isolation. The pellet containing the vessels was resuspended in dextran solution and centrifuged to remove myelin. Brain vessels were collected on a small cell strainer by centrifugation and washed twice prior to sedimentation. The supernatant was removed completely and the vessels were frozen on dry ice prior to protein extraction. $5 \mu \mathrm{g}$ of total protein of vesselenriched fraction and/or parenchyma fraction was subjected to SDS-PAGE and Western blotting. Created with Biorender.com.

To demonstrate fractionation of wild-type mouse brains, $5 \mu \mathrm{g}$ total protein of vessel extract or vessel-depleted parenchyma extract were subjected to Western blotting, detecting several vascular/endothelial, glial, and neuronal markers (Figure 2). Vascular endothelialspecific proteins endothelial nitric oxide synthase (eNOS) and vascular-endothelial cadherin (VE-cadherin), as well as vascular smooth muscle cell-specific $\alpha$-smooth muscle actin ( $\alpha$-SM-actin) were heavily enriched in the vessel fraction, demonstrating successful enrichment of blood vessels. By contrast, the neuronal protein synaptosomal-associated protein 25 (SNAP25) was mainly localized in the parenchyma fraction. Aquaporin-4 (Aqp4), which is primarily expressed in the astrocytes' vascular endfeet processes, was distinctively enriched in the vessel fraction, indicating attachment of perivascular endfeet membranes to the vessel fraction. This validates our and other groups' previous findings showing Aqp4 immunolabelling at the surface of isolated capillaries $[9,12]$ and shows that endothelial cells and astrocyte endfeet processes that form vital parts of the BBB can be purified due to their close association. 


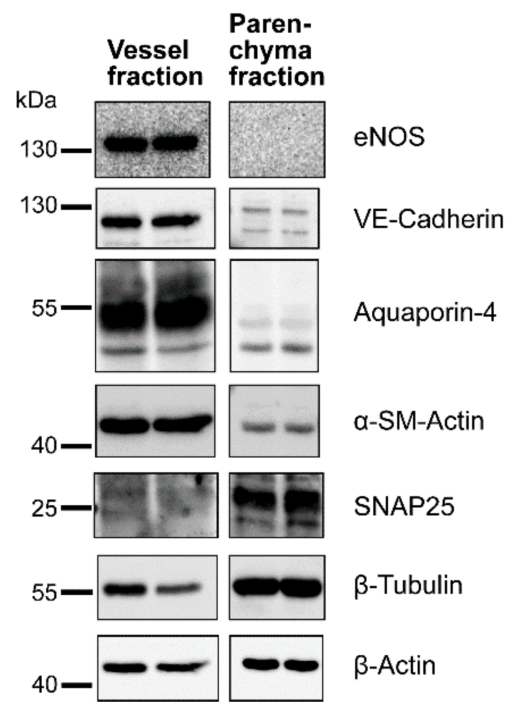

Figure 2. Separation of brain vessel-enriched fraction and vessel-depleted parenchyma compartment from single mouse brain hemispheres. Brain hemispheres of 2 mice were separated by centrifugation fractionation and $5 \mu \mathrm{g}$ of total protein was subjected to SDS-PAGE and Western blotting. Vascular/endothelial markers ( $\alpha$-SM-actin, eNOS, VE-cadherin) and astrocyte endfeet (aquaporin-4) are heavily enriched in the vessel fraction, while neuronal marker SNAP25 is detected mainly in the parenchyma fraction. $\alpha$-SM-actin, $\alpha$-smooth muscle actin; eNOS, endothelial nitric oxide synthase; SNAP25, synaptosomal-associated protein 25; VE-cadherin, vascular endothelial cadherin.

In vessel-enriched fractions, the loading control $\beta$-tubulin repeatedly returned lower signals compared to the parenchyma fraction for equal protein concentrations. Re-probing with $\beta$-actin as loading control resulted in comparable signals in both vessel and parenchyma fractions (Figure 2), suggesting the use of $\beta$-actin as a loading control for approaches that directly compare vessel and parenchyma fraction protein expressions.

\subsection{Testing of Tissue Requirements and Comparison with Previously Published Methods}

Brain vessel isolation protocols often require the use of freshly prepared tissue [9-11], while some reports describe the use of frozen brains [14]. In order to compare tissue usability with our modified method, brains from wild-type mice were harvested and split sagitally by the interhemispheric fissure into the two hemispheres. One hemisphere was flash frozen on dry ice, while the other hemisphere was processed freshly. Immunofluorescence staining using markers for mural cells ( $\alpha$-SM-actin), endothelial cells (eNOS) and astrocytes (Aqp4 and GFAP) resulted in similar staining patterns for vessels obtained from fresh and frozen tissue, confirming microvessel fractions with discrete BBB components (Figure 3a). Phase-contrast images of vessel fractions revealed no apparent morphological differences between vessels isolated from fresh and frozen wild-type mouse brain hemispheres (Figure 3b). Additional Western blot-based assessment of vascular markers presented with a lower VE-cadherin and claudin-5 signals in the vessel fractions isolated from frozen tissue, while signals for eNOS, $\alpha$-SM-actin, and loading control $\beta$-actin were comparable between freshly processed and frozen samples (Figure 3c). This indicates that separation of the vessel and parenchyma fraction can be performed equally well with both fresh and frozen tissue, however, freezing the tissue may interfere with antibody-based detection of some markers or generally affect the expression of these targets. 


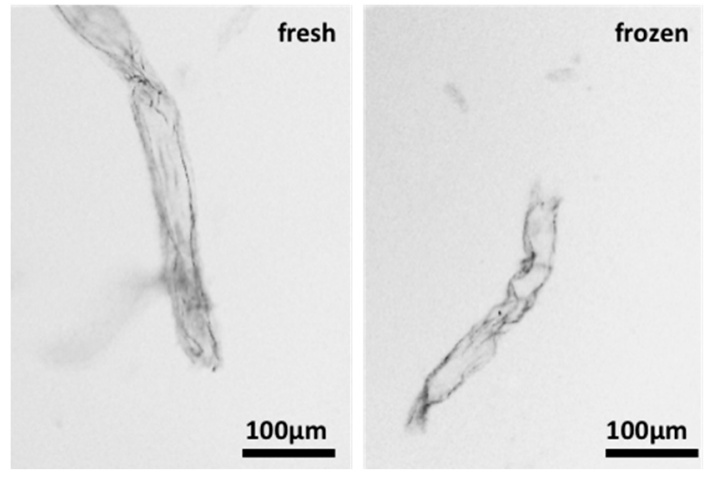

(a)

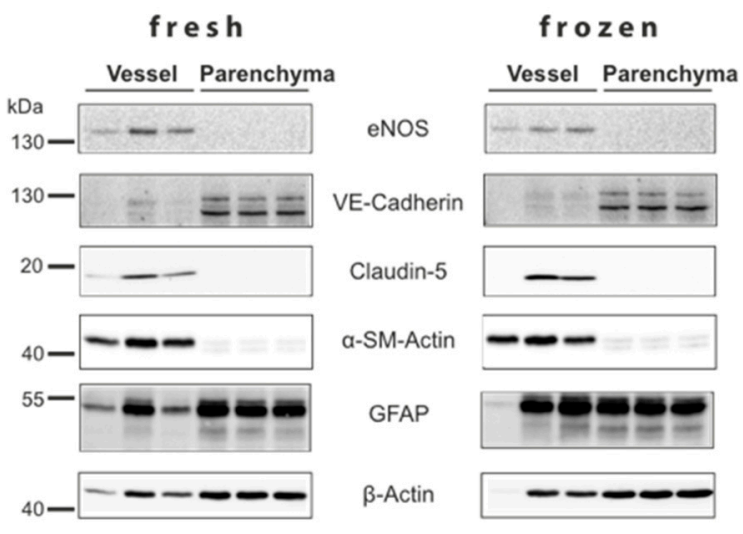

(c)
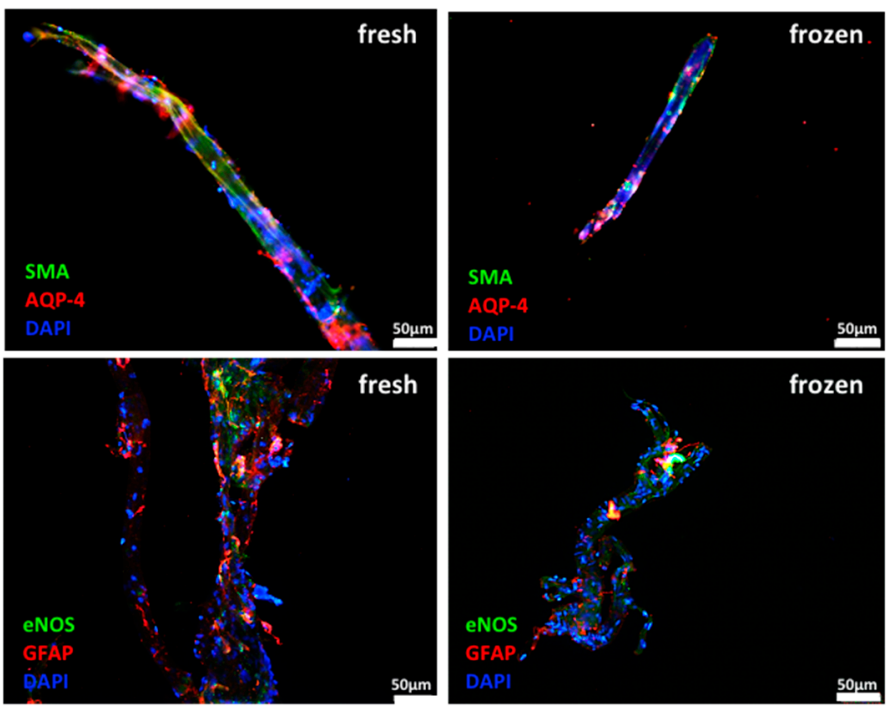

(b)
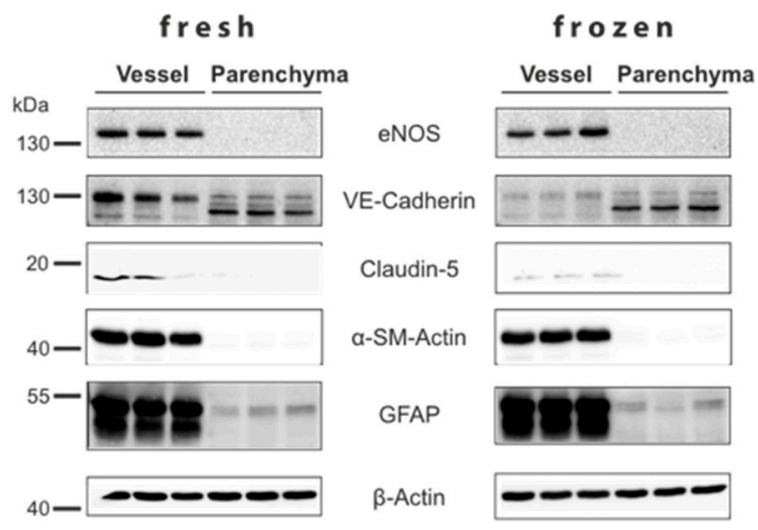

(d)

Figure 3. Testing of tissue requirements and comparison with a previously published method. Harvested brains were split into hemispheres. One hemisphere was immediately subjected to vessel- and parenchyma fractionation ("fresh"), while the other hemisphere was flash frozen on dry ice and thawed before fractionation ("frozen"). (a) Vessel fractions were plated on microscopy glass slides and visualized using phase contrast. Scale bars denote $100 \mu \mathrm{m}$. (b) Vessel fractions isolated from fresh and frozen brain tissue were stained for immunofluorescence with markers for mural cells ( $\alpha$-SM-actin), endothelial cells (eNOS) and astrocytes (Aqp4 and GFAP). Scale bars denote $50 \mu \mathrm{m}$. (c) $5 \mu \mathrm{g}$ of total protein was subjected to Western blotting. Fractions generated by the herein described method were compared to (d) fractions from a different protocol of cortical blood vessel isolation (Hawkes and McLaurin, 2009). $\alpha$-SM-actin, $\alpha$-smooth muscle actin; eNOS, endothelial nitric oxide synthase; GFAP, glial fibrillary acidic protein; VE-cadherin, vascular endothelial cadherin.

In this experiment, we also included detection of astrocytic glial fibrillary acidic protein (GFAP), which has been detected by immunofluorescence staining in brain capillaryenriched fractions [9]. In contrast to the previously described vague signals, we found distinct GFAP signals in vessel stainings (Figure $3 b$ ) and a considerable enrichment of GFAP protein expression in the vessel-enriched fraction (GFAP- $\beta$-actin ratio for vessel and parenchyma fraction: $9.893 \pm 1.626$ vs. $0.030 \pm 0.006$; Figure 3c). When comparing freshly prepared and frozen tissue, GFAP signal differences between vessel and parenchyma fractions were unchanged (GFAP- $\beta$-actin ratio for vessel and parenchyma fraction: $9.893 \pm 1.626$ vs. $7.287 \pm 1.109$; Figure 3c), further supporting the possibility of using fresh and frozen tissue alike for vessel/parenchyma fractionation depending on the protein of interest. 
In order to further validate and compare the efficacy of our protocol to a method that has previously been used with frozen tissue, we repeated the above experiment using a previously described vessel purification protocol $[11,14]$ that distinctly differs from our protocol (i.e., tissue homogenization in ammonium carbonate buffer vs. tissue homogenization in HBSS-HEPES, different centrifugation speed and length as well as the absence of myelin removal step using BSA-containing buffer). Wild-type mouse brains were divided sagitally by the interhemispheric fissure, and one hemisphere was flash frozen on dry ice before performing vessel and parenchyma fractionation while the other hemisphere was processed as fresh tissue. Western blot analyses show enrichment of vascular endothelial-specific protein eNOS and vascular smooth muscle cell-specific $\alpha$-SMactin, indicating successful purification of vessels. However, protein expression of certain vascular markers was weaker compared to our modified method (eNOS- $\beta$-actin ratio for the method by Hawkes and McLaurin [11] and the herein described modified method: $0.373 \pm 0.025$ vs. $1.44 \pm 0.394$ for fresh tissue), while signals for $\alpha$-SM-actin and claudin-5 were comparable between the two methods ( $\alpha$-SM-actin- $\beta$-actin ratio: $0.775 \pm 0.074$ vs. $0.627 \pm 0.062$; claudin-5- $\beta$-actin ratio: $0.548 \pm 0.126$ vs. $0.267 \pm 0.103$ for fresh tissue). Signals for VE-cadherin were not detectable with this method (Figure 3d). Comparison of fresh and frozen tissue did not show clear differences using this method, however, GFAP signals were not enhanced in the vessel fractions as compared to our method and expected for a successful enrichment (GFAP- $\beta$-actin ratio for vessel and parenchyma fraction: $0.700 \pm 0.240$ vs. $0.493 \pm 0.161$; Figure $3 \mathrm{~d}$ ).

Taken together, our vessel and parenchyma fractionation method performed as well as previously published vessel purification methods and required less tissue. Frozen brain tissue was generally usable for the separation by this fractionation method. Considering the markedly lower expression of some protein targets e.g., tight and adherens junction proteins claudin-5 and VE-cadherin, it cannot be ruled out that freezing the tissue may either interfere with antibody-based detection of some markers or generally affect expression of these targets.

\subsection{Application of Vessel and Parenchyma Fractionation in a Murine Stroke Model to Assess BBB Alterations}

Since our modified fractionation method can be used to yield sufficient vessel extract from a single mouse brain hemisphere, the procedure is especially suitable for investigations in mouse models that are expected to display regional differences within the same animal. Here, we used a well-established mouse model of stroke, in which permanent occlusion of the middle cerebral artery (MCAo) causes a lesion in the treated, ipsilateral hemisphere while the lesion-free contralateral hemisphere served as an internal control.

MCAo was performed on the left hemispheres of wild-type mice and the brains were harvested 3 days post-infarct. Western blot analyses detecting serum albumin show increased signals in the ipsilateral parenchyma fraction (Figure 4a), indicating that the stroke-induced BBB impairment allows albumin to cross the structural barrier formed by endothelial, mural and glial cells of cerebral blood vessels. Of note, the anti-albumin antibody used is specific for mouse and human albumin but does not react with bovine serum albumin, which was used during the vessel isolation procedure. Densitometric quantification of albumin signals shows a 3.9-fold albumin increase $(p=0.0054$; Figure $4 \mathrm{a})$, confirming that our fractionation method allowed for detection of a significant BBB dysfunction in the infarcted hemisphere. 

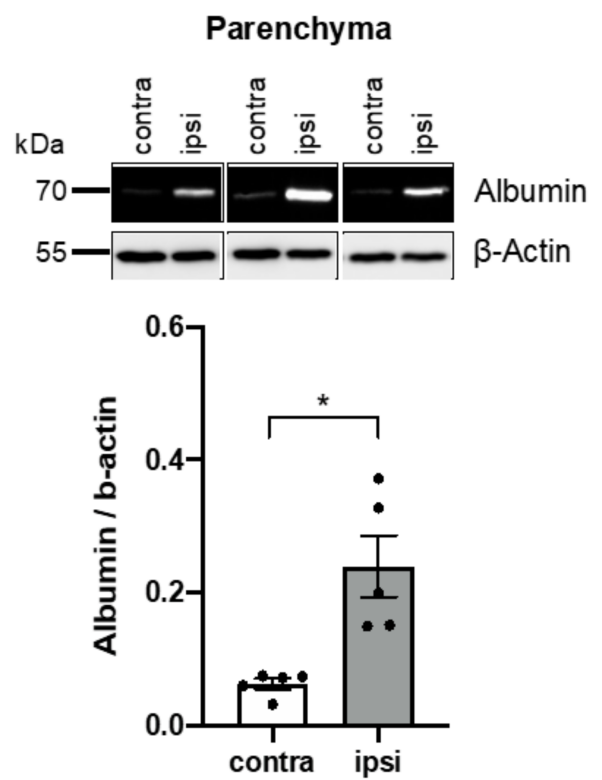

(a)
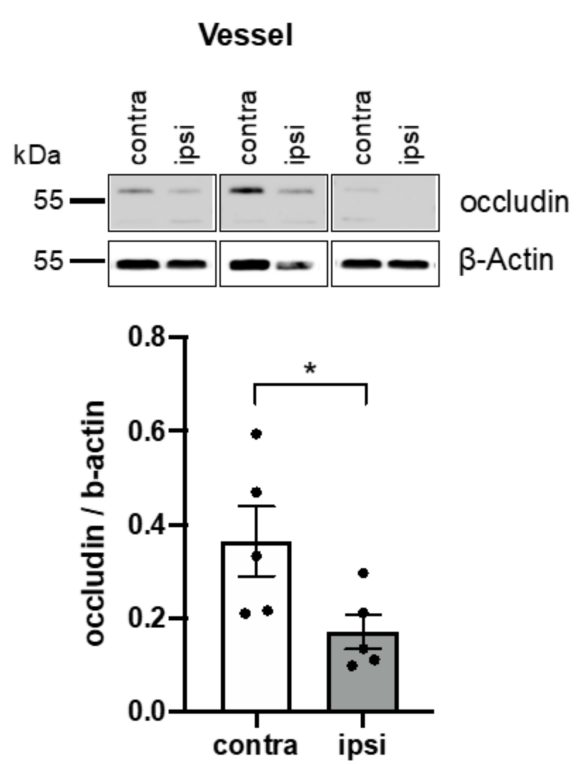

(c)
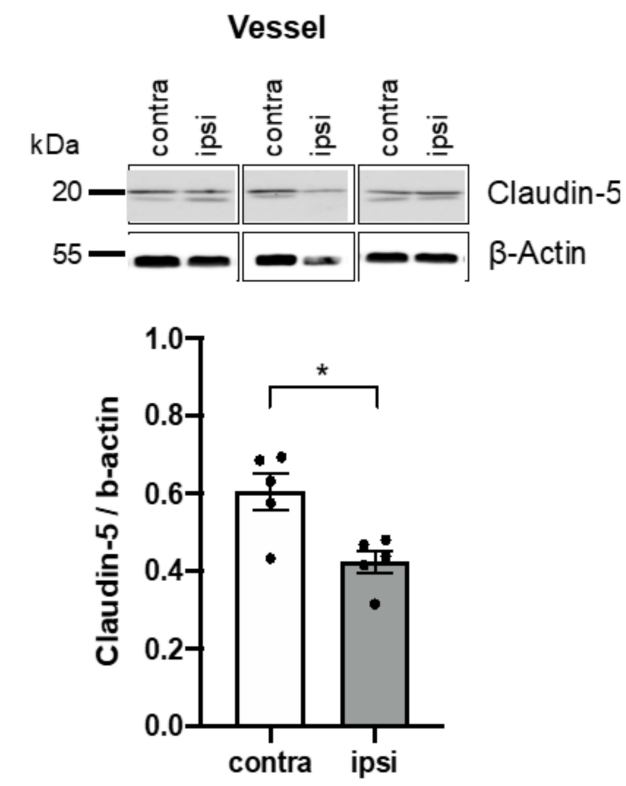

(b)

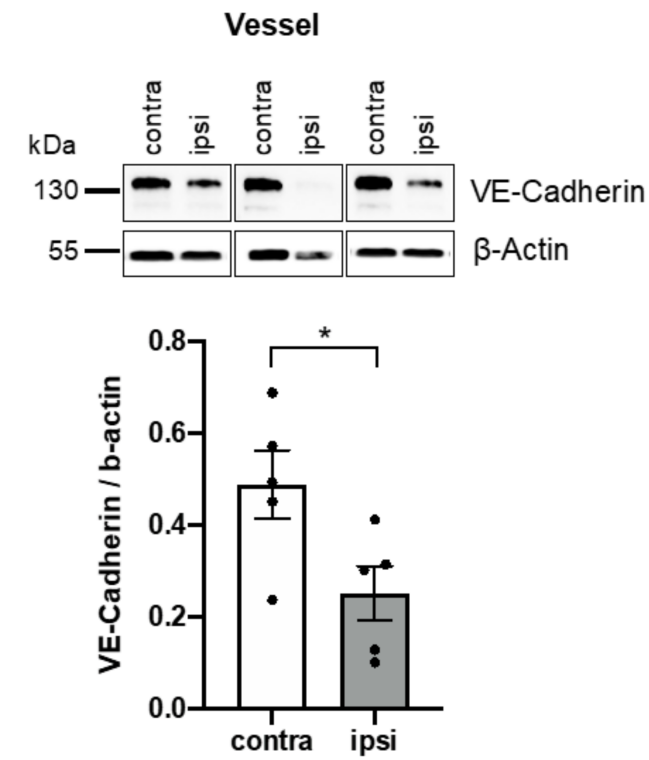

(d)

Figure 4. Cont. 


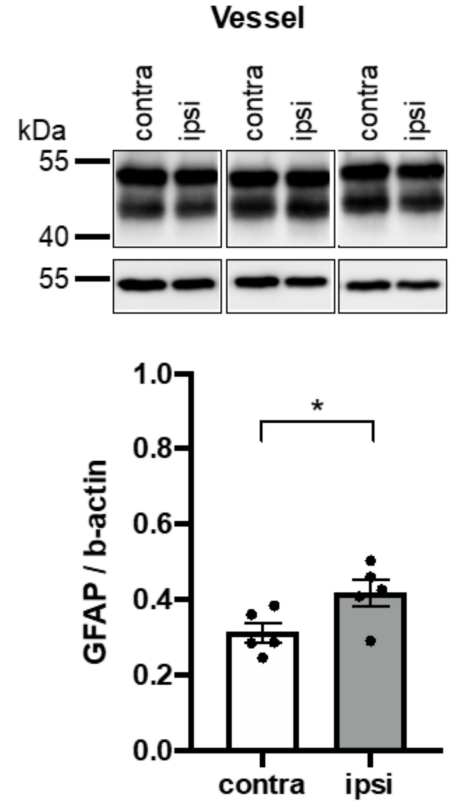

(e)
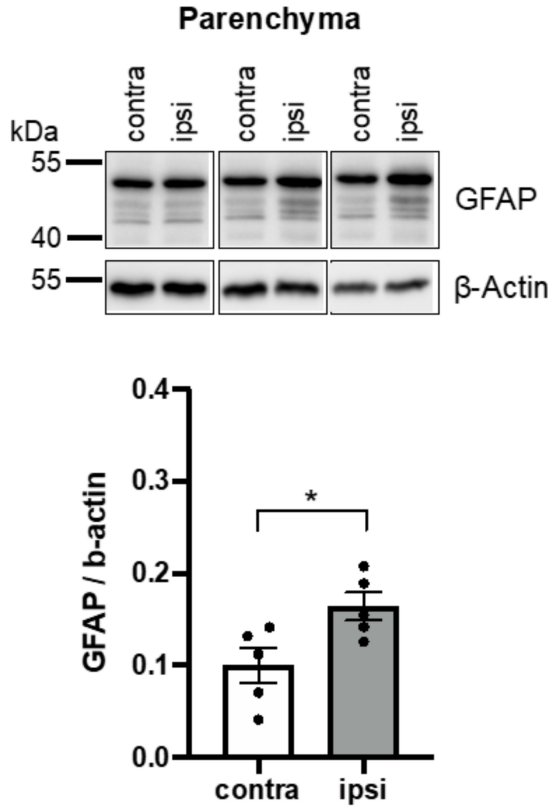

(f)

Figure 4. Application of vessel/parenchyma fractionation in a murine stroke model to detect BBB alterations. Wild-type mice were subjected to permanent occlusion of the left middle cerebral artery. After 3 days, brains were harvested and separated into the lesion-containing ipsilateral and the contralateral hemispheres. Vessel and parenchyma fractionation was performed, and $5 \mu \mathrm{g}$ of total protein was subjected to Western blotting. (a) A mouse- and human-specific anti-albumin antibody showed an increase of albumin in the ipsilateral parenchyma fractions of stroke mice, indicating hemisphere-specific BBB impairment. (b) Tight junction protein claudin-5 and (c) occludin show significantly lower expression patterns in ipsilateral vessel fractions. (d) Adherens junction protein VE-cadherin is significantly reduced in ipsilateral vessel fractions. (e) GFAP expression is increased in the ipsilateral hemispheres, both in vessel fractions and (f) in parenchyma fractions. $n=5$, mean \pm SEM, asterisks indicate $t$-test $p<0.05$. contra-contralateral (lesion-free) hemisphere, ipsi, ipsilateral (ischemic) hemisphere, GFAP, glial fibrillary acidic protein.

The BBB is formed by tight junctions (TJ) among endothelial cells, pericytes and astrocytic endfeet [15], all of which are enriched in our vessel fractions (see Figure 2). Ischemia alters several BBB components, both structurally and functionally [16]. Following MCAo, key constituents of cerebral endothelial cell TJ proteins claudin-5 and occludin [17] were significantly reduced in the vessel compartment isolated from the ipsilateral hemisphere compared to the contralateral control (claudin-5:1.5-fold reduction; Figure $4 \mathrm{~b}$ and occludin: 2.2-fold reduction; Figure 4c), exemplary for apparent stroke-induced BBB impairment. Additionally, VE-cadherin that plays a major role in regulating vascular permeability [18] and has been shown to be de-regulated during different neuro-pathologies [19] was significantly reduced in vessel fractions obtained from the lesioned hemisphere (1.9-fold reduction; Figure 4d). Moreover, astrocytic GFAP expression that increases in response to ischemia $[20,21]$ was significantly elevated 3 days post-stroke in both the vessel-enriched fractions and vessel-depleted parenchyma fractions, which may be related to BBB destruction [22] or repair after central nervous system (CNS) injury [23,24] and glial scar formation to compartmentalize the site of injury [25], respectively. Western blot quantifications showed a 1.3fold increase in GFAP signal in ipsilateral vessel fractions ( $p=0.030$; Figure 4e), and a 1.6-fold increase in ipsilateral parenchyma fractions ( $p=0.034$; Figure $4 \mathrm{f})$, compared to contralateral fractions, respectively, demonstrating apparent astrogliosis in both vessel and parenchyma compartment. This application confirms that vessel- and parenchyma fractionation can be applied in experiments using single mouse brain hemispheres, allowing for quantitative comparisons between hemispheres of both brain vessel and brain parenchyma fractions. 


\subsection{Application of Vessel-and Parenchyma Fractionation in a Rat Stroke Model}

To test whether our vessel- and parenchyma fractionation protocol is also applicable to rat brains, we used a recently-described thromboembolic stroke model [13]. Stroke was induced by local injection of $\alpha$-thrombin into the lumen of the middle cerebral artery of wild-type rats. Brains were harvested $24 \mathrm{~h}$ after stroke induction and separated into the lesion-containing ipsilateral and the contralateral hemispheres. Vessel and parenchyma fractionation was performed using 3-fold increased volumes to account for the larger rat brains, and the resulting samples were subjected to Western blotting. Vessel fractions displayed strong enrichments of vascular endothelial protein VE-cadherin and vascular smooth muscle cellspecific $\alpha$-SM-actin, indicating successful vessel purification (Figure 5a). Of note, anti-eNOS antibody (ab76198, Abcam, UK) did not react with rat protein (data not shown). Similar to our experiments in mice, a strong signal of astrocytic GFAP was detected in the vesselenriched fraction, and albumin signals were more pronounced in the parenchyma fraction (Figure 5a). To evaluate stroke-induced BBB leakiness by quantification of serum-albumin accumulation in the brain, parenchyma fractions of ipsi- and contralateral hemispheres were subjected to Western blotting. Densitometric analyses of albumin signals using $\beta$ actin signals as loading controls show a 3.9-fold increase in the ipsilateral compared to the contralateral fractions ( $p=0.018$; Figure $5 b)$.

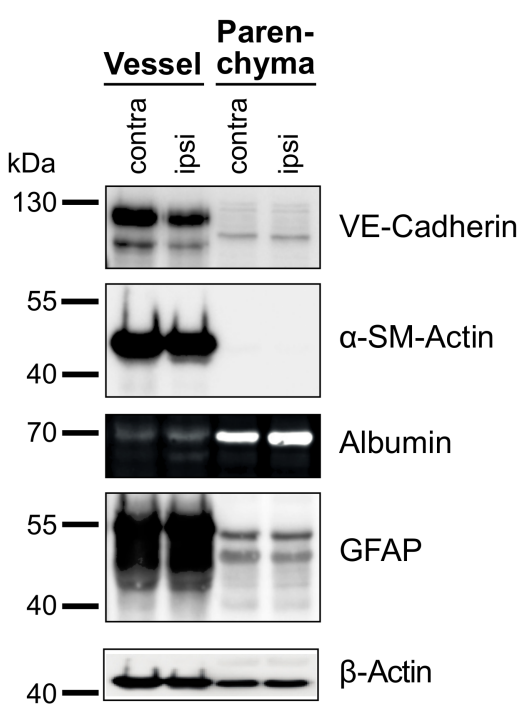

(a)

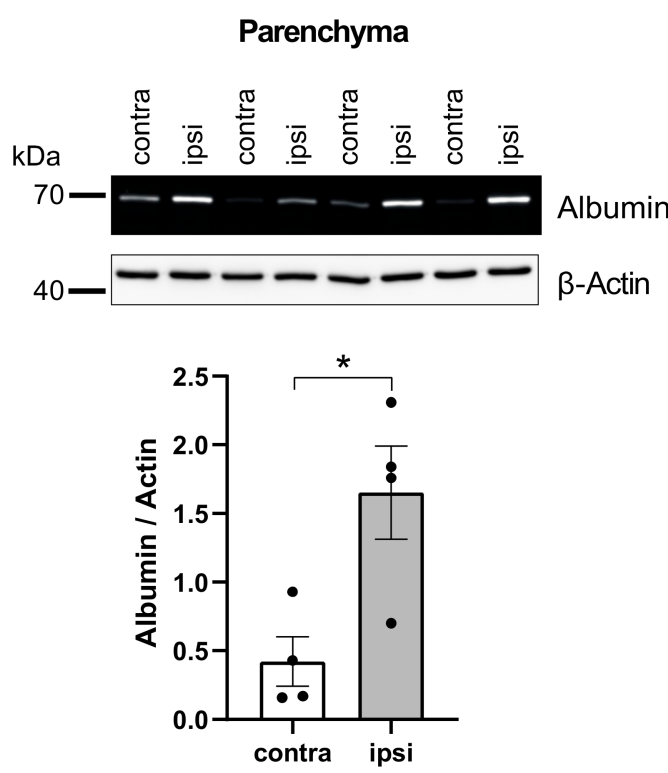

(b)

Figure 5. Demonstration of vessel and parenchyma fractionation in a thromboembolic stroke model in rats. Rat brains were harvested $24 \mathrm{~h}$ after thrombin-induced stroke and separated into the lesioncontaining ipsilateral and the contralateral hemispheres. Vessel and parenchyma fractionation was performed and $10 \mu \mathrm{g}$ of total protein was subjected to Western blotting. (a) Enrichment of vascular/endothelial markers and GFAP in the vessel fractions. (b) Parenchyma fractions of stroke rats show a significant increase of albumin in the ipsilateral hemisphere, indicating hemispherespecific BBB impairment. $n=4$, mean \pm SEM, asterisk indicates $t$-test $p<0.05$. contra-contralateral (lesion-free) hemisphere, ipsi, ipsilateral (ischemic) hemisphere, VE-cadherin, vascular endothelial cadherin; $\alpha$-SM-actin, $\alpha$-smooth muscle actin; GFAP, glial fibrillary acidic protein.

Despite the considerable variation, especially between ipsilateral signals and the different method of stroke induction, this increase very accurately matches the ipsilateral increase of albumin measured in the mouse stroke experiments (see Figure 4). This highlights the validity of centrifugation-based separation of tissue into vessel and parenchyma-enriched fractions both across species and in healthy and disease conditions and demonstrates a new application for investigations of BBB dysfunction. 


\section{Discussion}

In this study, we evaluated a modified mouse brain vessel-parenchyma fractionation method that permits quantitative protein analyses of the cerebrovascular niche and the vessel-depleted parenchyma fraction and thus, enables investigations requiring analysis of small tissue volumes, e.g., the direct comparison of the two brain hemispheres from the same animal. The method is based on a mechanical vessel isolation procedure [9] and does not require density gradient centrifugation or enzymatic digestion, rendering it technically straight-forward and more reproducible. Previous studies using similar vessel enrichment protocols have mainly focused on the purified vessel fraction alone $[9,26,27]$ or compared the purified vessels to total brain homogenate $[10,28]$, necessitating two tissue samples. Our approach has the advantage of enabling comparison of the vesselenriched fraction to the vessel-depleted parenchyma fraction of the same mouse brain sample, which has previously only been performed with larger tissue quantities, i.e., human material [29]. We demonstrated the applicability of our modified method in a murine stroke model where it allows the reliable quantification of serum-albumin accumulation in brain parenchyma of the ipsilateral hemisphere, ipsilateral vascular TJ and adherens junction protein reduction as well as the quantitative comparison of astrogliosis both in vessel and parenchyma fraction. We furthermore validated the method in a rat model of stroke and thus, confirming its suitability as a technique to reliably and quantitatively assess BBB dysfunction and alterations in the neurovascular niche in an unbiased way.

The use of frozen tissue samples for brain vessel isolation has been described [14,29,30], but the literature remains elusive about the effects of freezing or simply claim to require fresh tissue. We directly compared vessel-parenchyma fractionation using fresh and dry-ice frozen brain tissue, demonstrating general usability of frozen brain tissue for fractionation, although the expression or antibody-based detectability of some protein targets, such as VE-cadherin and claudin-5, may be affected by the freezing process.

BBB integrity is an important target for assessment in studies of neurodegeneration and has an important role in the evaluation of treatment [31-35]. BBB breakdown is widely assessed using microscopy analyses following FITC-albumin or Evans Blue (EB) extravasation into the brain parenchyma. Despite its limitations, EB with its albumin-binding capacity is still the most commonly used tracer for such studies [36]. For both EB and FITC-labeled tracers, animals need to be perfused after injection and circulation of the dyes, which precludes the use of blood or plasma for additional readouts (e.g., flow cytometry, Elisa etc.). Moreover, histology quantification is associated with artefacts due to tissue preparation that requires fixation or accompanying autofluorescence. Commonly employed histological methods are subject to observer bias and are not amenable to rigorous quantitative analysis. Our study shows that BBB integrity can be assayed by analysis of serum albumin in the parenchymal-enriched fractions after centrifugation separation of brain tissue, adding another option for quantitatively studying BBB dysfunction. Additional, compartmentalization of blood vessels and brain parenchyma using the herein described protocol allows for further quantitative assessment of molecular contributors to BBB impairment of interest (e.g., TJ and adherens junction proteins) [37,38]. Especially since proper BBB functioning requires endothelial cells to collaborate with glial cells, pericytes and extracellular matrix to form a "barrier" that separates the CNS from the systemic circulation and controls the permeation of circulating solutes into the brain [39], the herein described fractionation method is suitable to quantitatively study $\mathrm{BBB}$ alterations as important BBB forming cell-types are detectable in the vascular fraction.

During stroke, the ionic imbalance caused by disruption of oxygen supply to the brain rapidly activates proteolytic enzymes, which negatively affect the BBB [8]. In experimental stroke research, fluorescently labelled dextran or albumin as well as EB are the gold-standard methods to assess BBB impairment with the above-mentioned shortcomings. With our centrifugation-based fractionation method, we provide a quantitative and versatile method that allows for detection of BBB dysfunction in the infarcted hemisphere using Western blot approaches that permit comparing to the lesion-free contralateral 
hemisphere from the same animal which serves as an internal control. Our data provide compelling validation of our method by showing significantly increased serum-albumin protein expression in the ipsilateral parenchyma fraction, suggestive of apparent BBB leakiness 3 days post-stroke in a murine model as well as 1-day post-stroke in a rat model. In stroke lesion formation, the loss of BBB integrity was shown to not only associate to the deregulation of endothelial junction proteins, of which claudin-5, occludin and VEcadherin are significantly reduced in the vascular fraction of the ischemic hemisphere, but also coincides with perivascular astrogliosis [22]. The augmented GFAP protein expression observed in the ipsilateral vessel fraction compared to the lesion-free contralateral control evidence apparent astrogliosis [20] that may link to impairments of BBB integrity mediated through the release of vascular permeability factors such as, vascular endothelial growth factor [40], matrix metalloproteinases [41], endothelin [42], nitric oxide [43], or glutamate [44]. Alternatively, augmented astrogliosis associated to the cerebral vasculature may also point towards regenerative processes during the chronic phase post-stroke as astrocytes release vascular protective substances, including glial-derived neurotrophic factor [45,46], insulin-like growth factor-1 [47] or apolipoprotein E [48,49]. The concurrent significantly higher serum-albumin expression detected in the ipsilateral parenchyma fraction and the lower expression of different endothelial junction proteins in the ipsilateral vessel fractions, however, point to a leaky BBB and thus, suggest astrogliosis linked to BBB destruction rather than protection 3 days post-stroke.

Studies demonstrated that astrocyte responses to injury encompass a broad continuum of cellular changes [50], ranging from mild insults that may result in the upregulation of GFAP expression in a subset of astrocytes that do not express GFAP at appreciable levels under physiologic conditions to moderate or severe GFAP upregulation and hypertrophy. Histological assessment of GFAP ${ }^{+}$astrocytes is widely accepted, however, counting reactive astrocytes can be challenging due to extensive process thickening, elongation, ramification, and overlap, which potentially adds variability to the results thus, permitting reliable quantitative assessments. Our method provides an opportunity to quantify the degree of astroglial activation (e.g., during disease progression and regeneration after cerebral infarction) and additionally provides a certain degree of spatial information (i.e., vascular compartment vs. parenchyma-associated astrogliosis) through quantitative western blot-based evaluation of, for instance, GFAP expression. Western blotting of vessel and parenchyma enriched fractions could thus be an unbiased alternative to traditional cell counting.

Taken together, our study validates a modified protocol for centrifugation-based vessel and parenchyma fraction separation from a single mouse brain hemisphere for reliable quantitative assessment of BBB integrity and the neurovascular niche.

Author Contributions: Conceptualization, A.M. and I.L.; methodology, F.M.; validation, F.M. and H.M.; formal analysis, F.M. and A.M.; data curation, F.M., H.M., K.A., and A.M.; writing-original draft preparation, F.M., A.M., and I.L.; writing-review and editing, F.M., H.M., A.M., and I.L.; visualization, F.M. and A.M.; supervision, A.M.; project administration, A.M.; funding acquisition, A.M., I.L., and S.A. All authors have read and agreed to the published version of the manuscript.

Funding: This work was supported by the following funding sources: The Knut and Alice Wallenberg foundation [F 2015/2112, AM, IL], Swedish Research Council [VR; 2017-01243, AM; 2018-02340, IL], Crafoord Foundation [IL, SA], German Research Foundation [DFG; ME 4667/2-1; AM], Strokeriksförbundet [AM], Sparbanken Skåne [AM, SA], Brain Foundation [SA], Hedlund Stiftelse [M-2019-1101; AM], Åke Wibergs Stiftelse [M19-0380; AM], Albert Påhlssons Stiftelse [AM], and Demensfonden [AM].

Institutional Review Board Statement: This investigation conforms to the Guide for Care and Use of Laboratory Animals published by the European Union (Directive 2010/63/EU) and with the ARRIVE guidelines. All animal care and experimental protocols were approved by the institutional animal ethics committee at Lund University (Dnr.: 5.8.18-12657/2017 and 5.8.18-10593/2020) and LANUV NRW (81-02.04.2019.A214/01) and were conducted in accordance with European animal protection laws. 
Informed Consent Statement: Not applicable.

Conflicts of Interest: The authors declare no conflict of interest.

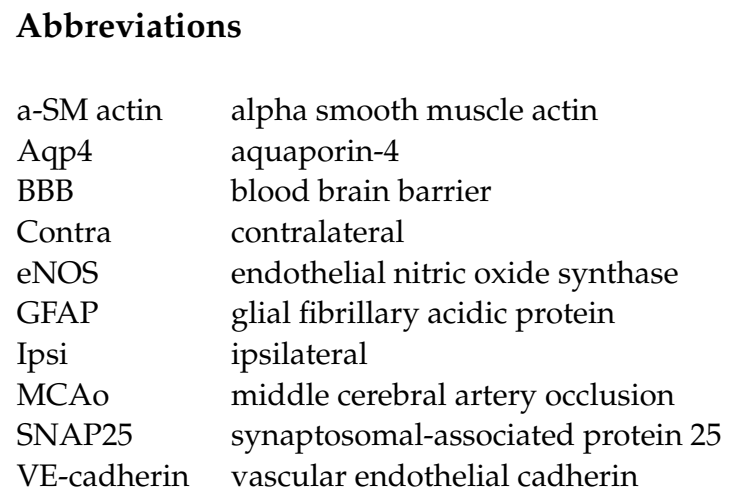

\section{References}

1. Daneman, R.; Prat, A. The blood-brain barrier. Cold Spring Harb. Perspect. Biol. 2015, 7, a020412. [CrossRef]

2. Pardridge, W.M. Blood-brain barrier delivery. Drug Discov. Today 2007, 12, 54-61. [CrossRef]

3. Sweeney, M.D.; Kisler, K.; Montagne, A.; Toga, A.W.; Zlokovic, B.V. The role of brain vasculature in neurodegenerative disorders. Nat. Neurosci. 2018, 21, 1318-1331. [CrossRef]

4. Di Giovanna, A.P.; Tibo, A.; Silvestri, L.; Mullenbroich, M.C.; Costantini, I.; Allegra Mascaro, A.L.; Sacconi, L.; Frasconi, P.; Pavone, F.S. Whole-Brain Vasculature Reconstruction at the Single Capillary Level. Sci. Rep. 2018, 8, 12573. [CrossRef] [PubMed]

5. Abbott, N.J. Blood-brain barrier structure and function and the challenges for CNS drug delivery. J. Inherit. Metab. Dis. 2013, 36, 437-449. [CrossRef] [PubMed]

6. Yu, X.; Ji, C.; Shao, A. Neurovascular Unit Dysfunction and Neurodegenerative Disorders. Front. Neurosci. 2020, $14,334$. [CrossRef] [PubMed]

7. Ahmad, A.; Patel, V.; Xiao, J.; Khan, M.M. The Role of Neurovascular System in Neurodegenerative Diseases. Mol. Neurobiol. 2020, 57, 4373-4393. [CrossRef] [PubMed]

8. Krueger, M.; Mages, B.; Hobusch, C.; Michalski, D. Endothelial edema precedes blood-brain barrier breakdown in early time points after experimental focal cerebral ischemia. Acta Neuropathol. Commun. 2019, 7, 17. [CrossRef] [PubMed]

9. Boulay, A.C.; Saubamea, B.; Decleves, X.; Cohen-Salmon, M. Purification of Mouse Brain Vessels. J. Vis. Exp. 2015, 105, e53208. [CrossRef]

10. Lee, Y.K.; Uchida, H.; Smith, H.; Ito, A.; Sanchez, T. The isolation and molecular characterization of cerebral microvessels. Nat. Protoc. 2019, 14, 3059-3081. [CrossRef]

11. Hawkes, C.A.; McLaurin, J. Selective targeting of perivascular macrophages for clearance of beta-amyloid in cerebral amyloid angiopathy. Proc. Natl. Acad. Sci. USA 2009, 106, 1261-1266. [CrossRef] [PubMed]

12. Munk, A.S.; Wang, W.; Bechet, N.B.; Eltanahy, A.M.; Cheng, A.X.; Sigurdsson, B.; Benraiss, A.; Mae, M.A.; Kress, B.T.; Kelley, D.H.; et al. PDGF-B Is Required for Development of the Glymphatic System. Cell Rep. 2019, 26, 2955-2969.e3. [CrossRef] [PubMed]

13. Arkelius, K.; Vivien, D.; Orset, C.; Ansar, S. Validation of a stroke model in rat compatible with rt-PA-induced thrombolysis: New hope for successful translation to the clinic. Sci. Rep. 2020, 10, 12191. [CrossRef] [PubMed]

14. Joo, I.L.; Lai, A.Y.; Bazzigaluppi, P.; Koletar, M.M.; Dorr, A.; Brown, M.E.; Thomason, L.A.; Sled, J.G.; McLaurin, J.; Stefanovic, B. Early neurovascular dysfunction in a transgenic rat model of Alzheimer's disease. Sci. Rep. 2017, 7, 46427. [CrossRef] [PubMed]

15. Zhao, Z.; Nelson, A.R.; Betsholtz, C.; Zlokovic, B.V. Establishment and Dysfunction of the Blood-Brain Barrier. Cell 2015, 163, 1064-1078. [CrossRef] [PubMed]

16. Abdullahi, W.; Tripathi, D.; Ronaldson, P.T. Blood-brain barrier dysfunction in ischemic stroke: Targeting tight junctions and transporters for vascular protection. Am. J. Physiol. Cell Physiol. 2018, 315, C343-C356. [CrossRef] [PubMed]

17. Luissint, A.C.; Artus, C.; Glacial, F.; Ganeshamoorthy, K.; Couraud, P.O. Tight junctions at the blood brain barrier: Physiological architecture and disease-associated dysregulation. Fluids Barriers CNS 2012, 9, 23. [CrossRef]

18. Li, W.; Chen, Z.; Chin, I.; Chen, Z.; Dai, H. The Role of VE-cadherin in Blood-brain Barrier Integrity Under Central Nervous System Pathological Conditions. Curr. Neuropharmacol. 2018, 16, 1375-1384. [CrossRef]

19. Liu, W.Y.; Wang, Z.B.; Wang, Y.; Tong, L.C.; Li, Y.; Wei, X.; Luan, P.; Li, L. Increasing the Permeability of the Blood-brain Barrier in Three Different Models in vivo. CNS Neurosci. Ther. 2015, 21, 568-574. [CrossRef]

20. Becerra-Calixto, A.; Cardona-Gomez, G.P. The Role of Astrocytes in Neuroprotection after Brain Stroke: Potential in Cell Therapy. Front. Mol. Neurosci. 2017, 10, 88. [CrossRef]

21. Ikeshima-Kataoka, H.; Abe, Y.; Yasui, M. Aquaporin 4-dependent expression of glial fibrillary acidic protein and tenascin-C in activated astrocytes in stab wound mouse brain and in primary culture. J. Neurosci. Res. 2015, 93, 121-129. [CrossRef] [PubMed] 
22. Alvarez, J.I.; Saint-Laurent, O.; Godschalk, A.; Terouz, S.; Briels, C.; Larouche, S.; Bourbonniere, L.; Larochelle, C.; Prat, A. Focal disturbances in the blood-brain barrier are associated with formation of neuroinflammatory lesions. Neurobiol. Dis. 2015, 74, 14-24. [CrossRef] [PubMed]

23. Kubotera, H.; Ikeshima-Kataoka, H.; Hatashita, Y.; Allegra Mascaro, A.L.; Pavone, F.S.; Inoue, T. Astrocytic endfeet re-cover blood vessels after removal by laser ablation. Sci. Rep. 2019, 9, 1263. [CrossRef] [PubMed]

24. Hayakawa, K.; Pham, L.D.; Arai, K.; Lo, E.H. Reactive astrocytes promote adhesive interactions between brain endothelium and endothelial progenitor cells via HMGB1 and beta-2 integrin signaling. Stem Cell Res. 2014, 12, 531-538. [CrossRef] [PubMed]

25. Anderson, M.A.; Burda, J.E.; Ren, Y.; Ao, Y.; O’Shea, T.M.; Kawaguchi, R.; Coppola, G.; Khakh, B.S.; Deming, T.J.; Sofroniew, M.V. Astrocyte scar formation aids central nervous system axon regeneration. Nature 2016, 532, 195-200. [CrossRef]

26. Begum, G.; Song, S.; Wang, S.; Zhao, H.; Bhuiyan, M.I.H.; Li, E.; Nepomuceno, R.; Ye, Q.; Sun, M.; Calderon, M.J.; et al. Selective knockout of astrocytic $\mathrm{Na}(+) / \mathrm{H}(+)$ exchanger isoform 1 reduces astrogliosis, BBB damage, infarction, and improves neurological function after ischemic stroke. Glia 2018, 66, 126-144. [CrossRef]

27. Yanagida, K.; Liu, C.H.; Faraco, G.; Galvani, S.; Smith, H.K.; Burg, N.; Anrather, J.; Sanchez, T.; Iadecola, C.; Hla, T. Size-selective opening of the blood-brain barrier by targeting endothelial sphingosine 1-phosphate receptor 1. Proc. Natl. Acad. Sci. USA 2017, 114, 4531-4536. [CrossRef]

28. Gama Sosa, M.A.; De Gasperi, R.; Perez Garcia, G.S.; Perez, G.M.; Searcy, C.; Vargas, D.; Spencer, A.; Janssen, P.L.; Tschiffely, A.E.; McCarron, R.M.; et al. Low-level blast exposure disrupts gliovascular and neurovascular connections and induces a chronic vascular pathology in rat brain. Acta Neuropathol. Commun. 2019, 7, 6. [CrossRef]

29. Bourassa, P.; Tremblay, C.; Schneider, J.A.; Bennett, D.A.; Calon, F. Beta-amyloid pathology in human brain microvessel extracts from the parietal cortex: Relation with cerebral amyloid angiopathy and Alzheimer's disease. Acta Neuropathol. 2019, 137, 801-823. [CrossRef]

30. Pardridge, W.M.; Yang, J.; Eisenberg, J.; Tourtellotte, W.W. Isolation of intact capillaries and capillary plasma membranes from frozen human brain. J. Neurosci. Res. 1987, 18, 352-357. [CrossRef]

31. Corem, N.; Anzi, S.; Gelb, S.; Ben-Zvi, A. Leptin receptor deficiency induces early, transient and hyperglycaemia-independent blood-brain barrier dysfunction. Sci. Rep. 2019, 9, 2884. [CrossRef] [PubMed]

32. Di Pardo, A.; Amico, E.; Scalabri, F.; Pepe, G.; Castaldo, S.; Elifani, F.; Capocci, L.; De Sanctis, C.; Comerci, L.; Pompeo, F.; et al. Impairment of blood-brain barrier is an early event in R6/2 mouse model of Huntington Disease. Sci. Rep. $2017,7,41316$. [CrossRef] [PubMed]

33. Gustafsson, S.; Gustavsson, T.; Roshanbin, S.; Hultqvist, G.; Hammarlund-Udenaes, M.; Sehlin, D.; Syvanen, S. Blood-brain barrier integrity in a mouse model of Alzheimer's disease with or without acute 3D6 immunotherapy. Neuropharmacology 2018, 143, 1-9. [CrossRef]

34. Salas-Perdomo, A.; Miro-Mur, F.; Gallizioli, M.; Brait, V.H.; Justicia, C.; Meissner, A.; Urra, X.; Chamorro, A.; Planas, A.M. Role of the S1P pathway and inhibition by fingolimod in preventing hemorrhagic transformation after stroke. Sci. Rep. 2019, 9, 8309. [CrossRef] [PubMed]

35. Meissner, A.; Minnerup, J.; Soria, G.; Planas, A.M. Structural and functional brain alterations in a murine model of Angiotensin II-induced hypertension. J. Neurochem. 2017, 140, 509-521. [CrossRef]

36. Saunders, N.R.; Dziegielewska, K.M.; Mollgard, K.; Habgood, M.D. Markers for blood-brain barrier integrity: How appropriate is Evans blue in the twenty-first century and what are the alternatives? Front. Neurosci. 2015, 9, 385. [CrossRef]

37. Wimmer, I.; Tietz, S.; Nishihara, H.; Deutsch, U.; Sallusto, F.; Gosselet, F.; Lyck, R.; Muller, W.A.; Lassmann, H.; Engelhardt, B. PECAM-1 Stabilizes Blood-Brain Barrier Integrity and Favors Paracellular T-Cell Diapedesis Across the Blood-Brain Barrier During Neuroinflammation. Front. Immunol. 2019, 10, 711. [CrossRef]

38. Winger, R.C.; Koblinski, J.E.; Kanda, T.; Ransohoff, R.M.; Muller, W.A. Rapid remodeling of tight junctions during paracellular diapedesis in a human model of the blood-brain barrier. J. Immunol. 2014, 193, 2427-2437. [CrossRef]

39. Ronaldson, P.T.; Davis, T.P. Blood-brain barrier integrity and glial support: Mechanisms that can be targeted for novel therapeutic approaches in stroke. Curr. Pharm. Des. 2012, 18, 3624-3644. [CrossRef]

40. Argaw, A.T.; Asp, L.; Zhang, J.; Navrazhina, K.; Pham, T.; Mariani, J.N.; Mahase, S.; Dutta, D.J.; Seto, J.; Kramer, E.G.; et al. Astrocyte-derived VEGF-A drives blood-brain barrier disruption in CNS inflammatory disease. J. Clin. Investig. 2012, 122, 2454-2468. [CrossRef]

41. Min, H.; Hong, J.; Cho, I.H.; Jang, Y.H.; Lee, H.; Kim, D.; Yu, S.W.; Lee, S.; Lee, S.J. TLR2-induced astrocyte MMP9 activation compromises the blood brain barrier and exacerbates intracerebral hemorrhage in animal models. Mol. Brain 2015, 8, 23. [CrossRef] [PubMed]

42. Yeung, P.K.; Shen, J.; Chung, S.S.; Chung, S.K. Targeted over-expression of endothelin-1 in astrocytes leads to more severe brain damage and vasospasm after subarachnoid hemorrhage. BMC Neurosci. 2013, 14, 131. [CrossRef] [PubMed]

43. Liu, B.; Neufeld, A.H. Expression of nitric oxide synthase-2 (NOS-2) in reactive astrocytes of the human glaucomatous optic nerve head. Glia 2000, 30, 178-186. [CrossRef]

44. Lu, L.; Hogan-Cann, A.D.; Globa, A.K.; Lu, P.; Nagy, J.I.; Bamji, S.X.; Anderson, C.M. Astrocytes drive cortical vasodilatory signaling by activating endothelial NMDA receptors. J. Cereb. Blood Flow Metab. 2019, 39, 481-496. [CrossRef]

45. Chen, M.; Ba, H.; Lu, C.; Dai, J.; Sun, J. Glial Cell Line-Derived Neurotrophic Factor (GDNF) Promotes Angiogenesis through the Demethylation of the Fibromodulin (FMOD) Promoter in Glioblastoma. Med. Sci. Monit. 2018, 24, 6137-6143. [CrossRef] 
46. Xiao, W.; Wang, W.; Chen, W.; Sun, L.; Li, X.; Zhang, C.; Yang, H. GDNF is involved in the barrier-inducing effect of enteric glial cells on intestinal epithelial cells under acute ischemia reperfusion stimulation. Mol. Neurobiol. 2014, 50, 274-289. [CrossRef] [PubMed]

47. Okoreeh, A.K.; Bake, S.; Sohrabji, F. Astrocyte-specific insulin-like growth factor-1 gene transfer in aging female rats improves stroke outcomes. Glia 2017, 65, 1043-1058. [CrossRef]

48. Cao, F.; Jiang, Y.; Wu, Y.; Zhong, J.; Liu, J.; Qin, X.; Chen, L.; Vitek, M.P.; Li, F.; Xu, L.; et al. Apolipoprotein E-Mimetic COG1410 Reduces Acute Vasogenic Edema following Traumatic Brain Injury. J. Neurotrauma 2016, 33, 175-182. [CrossRef]

49. Teng, Z.; Guo, Z.; Zhong, J.; Cheng, C.; Huang, Z.; Wu, Y.; Tang, S.; Luo, C.; Peng, X.; Wu, H.; et al. ApoE Influences the Blood-Brain Barrier Through the NF-kappaB/MMP-9 Pathway After Traumatic Brain Injury. Sci. Rep. 2017, 7, 6649. [CrossRef]

50. Anderson, M.A.; Ao, Y.; Sofroniew, M.V. Heterogeneity of reactive astrocytes. Neurosci. Lett. 2014, 565, 23-29. [CrossRef] 